\title{
BMJ Open Risk factors for admission at three urban emergency departments in England: a cross-sectional analysis of attendances over 1 month
}

\author{
Sharif A Ismail, ${ }^{1}$ Ian Pope, ${ }^{2}$ Benjamin Bloom, ${ }^{3}$ Raquel Catalao, ${ }^{1}$ Emilie Green, ${ }^{1}$ \\ Rebecca E Longbottom, ${ }^{1}$ Gwyneth Jansen, ${ }^{4}$ David McCoy, ${ }^{5}$ Tim Harris ${ }^{3}$
}

To cite: Ismail SA, Pope I, Bloom B, et al. Risk factors for admission at three urban emergency departments in England: a cross-sectional analysis of attendances over 1 month. BMJ Open 2017;7:e011547. doi:10.1136/ bmjopen-2016-011547

- Prepublication history and additional material for this paper are available online. To view these files please visit the journal online (http://dx.doi. org/10.1136/bmjopen-2016011547).

Received 17 February 2016 Revised 16 May 2016 Accepted 12 July 2016

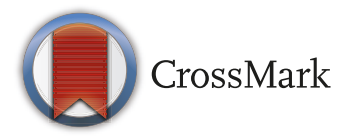

${ }^{1}$ Barts Health NHS Trust, London, UK

${ }^{2}$ Homerton University Hospital NHS Foundation Trust, London, UK

${ }^{3}$ Emergency Department, Royal London Hospital, London, UK ${ }^{4}$ Queen Mary University of London, London, UK

${ }^{5}$ Centre for Primary Care and Public Health, Queen Mary University of London, London, UK

Correspondence to Dr lan Pope; ianpope@gmail. com

\section{ABSTRACT}

Objective To investigate factors associated with unscheduled admission following presentation to emergency departments (EDs) at three hospitals in England.

Design and setting Cross-sectional analysis of attendance data for patients from three urban EDs in England: a large teaching hospital and major trauma centre (site 1) and two district general hospitals (sites 2 and 3). Variables included patient age, gender, ethnicity, deprivation score, arrival date and time, arrival by ambulance or otherwise, a variety of ED workload measures, inpatient bed occupancy rates and admission outcome. Coding inconsistencies in routine ED data used for this study meant that diagnosis could not be included.

Outcome measure The primary outcome for the study was unscheduled admission.

Participants All adults aged 16 and older attending the three inner London EDs in December 2013. Data on 19 734 unique patient attendances were gathered.

Results Outcome data were available for 19721 attendances (>99\%), of whom 6263 (32\%) were admitted to hospital. Site 1 was set as the baseline site for analysis of admission risk. Risk of admission was significantly greater at sites 2 and 3 (adjusted OR (AOR) relative to site 1 for site 2 was $1.89,95 \%$ $\mathrm{Cl} 1.74$ to $2.05, \mathrm{p}<0.001)$ and for patients of black or black British ethnicity (AOR 1.29, 1.16 to 1.44 , $p<0.001)$. Deprivation was strongly associated with admission. Analysis of departmental and hospitalwide workload pressures gave conflicting results, but proximity to the " 4 -hour target" (a rule that limits patient stays in EDs to 4 hours in the National Health Service in England) emerged as a strong driver for admission in this analysis (AOR $3.61,95 \% \mathrm{Cl} 3.30$ to $3.95, p<0.001$ ).

Conclusion This study found statistically significant variations in odds of admission between hospital sites when adjusting for various patient demographic and presentation factors, suggesting important variations in ED-level and clinician-level behaviour relating to admission decisions. The 4-hour target is a strong driver for emergency admission.

\section{Strengths and limitations of this study}

- Emergency admissions account for a substantial and growing proportion of hospital bed days in England, but while previous research has identified age, ethnicity, comorbidity, socioeconomic status, sex and referral source as factors influencing risk of admission following emergency attendance, organisational factors including emergency department (ED) workload and staffing have not been widely investigated.

- This study is among the first to investigate emergency admission patterns using routinely gathered ED data, incorporating patient demographic factors, ED workload factors and inpatient bed occupancy rates.

- The use of routine ED data in this analysis exposed problems with coding and definitions in electronic record systems, particularly relating to patient diagnosis which was ultimately excluded from the analysis. This may have an important bearing on admission risk and is a limitation to this study.

- The analysis demonstrates marked variations in risk of admission between EDs despite adjustment for a range of patient demographic and organisational factors. The proportion of patients who leave without receiving treatment at each time point emerges as a strong predictor of admission risk, as does disposition decision making immediately before the 4-hour target for EDs in England.

\section{INTRODUCTION}

Emergency admissions-defined as unpredicted admissions at short notice because of clinical need-account for around $67 \%$ of hospital bed days in England. ${ }^{1}$ Avoiding such admissions, especially for conditions thought appropriate for non-emergent ambulatory pathways, is a priority for the National Health Service (NHS). This is because of significantly increased associated costs, negative impacts of unscheduled admissions on elective care and the risk to inpatients from nosocomial infections and venous thromboembolic disease. 
However, the upward trend in admission rates in England in recent years has been marked, rising by $5.2 \%$ between 2013 and 2014 alone. $^{2-4}$

The reasons for rising admission rates from emergency departments (EDs) remain poorly understood. Previous research aimed at identifying groups of patients at increased risk for admission has demonstrated significant associations among age, sex, ethnicity, presence of comorbid conditions, socioeconomic indices (deprivation may explain up to $45 \%$ of the variation in $\mathrm{ED}$ admission rates between general practices in England) and risk of emergency admission. ${ }^{2}{ }^{5-7}$ These findings have prompted the development of increasingly sophisticated predictive tools to identify patients at high risk for admission and readmission. ${ }^{8-10}$ However, focusing on patients who frequently attend ED and on hospital readmissions may overestimate the contribution of a relatively small group to the rising burden of emergency admissions overall-when most admissions actually come from lower risk groups. ${ }^{11}$ The influence of changing models of delivery in primary and urgent care-including out-ofhours care, telemedicine and case management among many others-has been investigated without evidence of a clear effect on ED admission rates, ${ }^{12-14}$ although poor continuity of primary care and clinician behaviour have both emerged as possible factors in increased admission rates from primary care. ${ }^{15} 16$

By contrast, factors that may affect a patient's risk of admission on presentation to the ED have received very little attention. Clinician behaviour in the ED context is addressed by a small number of studies from Canada and the USA. ${ }^{17}{ }^{18}$ Similarly, the operational and organisational features of an ED that may contribute to admission risk have been poorly studied, although there is some evidence that the 4-hour target-a policy introduced in England in 2004 to limit patients' time in EDs to 4 hourshas led to a rise in short-stay admissions. ${ }^{19}$ There is also evidence that levels of ED crowding increase rates of admission. ${ }^{20}$ Evidence on the effect of other workload factors on emergency admission is conflicting, although higher inpatient bed occupancy may reduce the probability of admission. ${ }^{21}$

To help build our understanding of the relative contributions of patient, clinician and organisational factors to emergency admission rates, we conducted an analysis of the factors involved in clinician decisions to admit (both long and short stays) or discharge ED attenders in three inner-city EDs in London. This paper presents the results of a cross-sectional analysis of a sample of all presentations across the three EDs over a period of one calendar month (December), which was conducted to quantify the effect of a selection of a patient and organisational factors on the outcome of each presentation (ie, admission or discharge). This is accompanied by a linked qualitative study $^{22}$ exploring organisational factors affecting admission rates in more depth.

\section{METHODS}

\section{Study sites}

This was a cross-sectional observational study examining routinely collected data on all ED attendances at three inner-city EDs in London. Site 1 is a major, urban teaching hospital (a major trauma centre, equivalent to a level one trauma centre, with a hyperacute stroke unit), while sites 2 and 3 are urban, district general hospitals. Of these three sites, sites 1 and 2 have formal ED clinical decision units (CDUs) to accommodate short-stay admissions (typically less than 24 hours), while site 3 has an 'observational unit' shared between the ED and various inpatient specialties for short-stay admissions. For the purposes of this study, admission to the observational unit at site 3 was regarded as equivalent to admission to the CDUs at sites 1 and 2 (see below). All three sites have associated urgent care centres staffed by a general practitioner and specialist nurse, which see and filter a large volume of lower acuity presentations. Key characteristics of each department are outlined in table 1 .

\section{Data collection}

The study population consisted of all ED attendees aged 16 and older presenting in December 2013, including both ambulatory and ambulance service presentations. The selected time period for data collection was convenience based. We collected basic demographic information (patient age, gender, ethnicity), arrival date and time, day of the week, whether the patient had arrived by ambulance or by another means, referral source, the final ED diagnosis, length of stay, whether the patient remained in the ED for longer than 4 hours and the admission outcome. Data on acuity of patient presentation (in the form of triage scores by individual presentation) could not be obtained for this study. Supplementary data for patients admitted to the CDU included discharge date and time and diagnosis on discharge. Data across the three sites were extracted independently by data collectors overseen and trained by the second author.

Extensive data transformation was performed prior to analysis. Patient age data were converted into four banded groups: 16-34, 35-64 and 65-84 and 85 and older. This approach was dictated partly by the need for parsimony in the number of categories within each predictor variable and differences in the distribution of patients by age group across the three study sites (the proportion of presenting patients in the 85 and older category at site 2 was more than three times greater than each of sites 1 and 3). Primarily, however, it was driven by clinical evidence on the prevalence of multimorbidity and frailty among the 'oldest old' (85 and older), when compared with younger patients, ${ }^{23} 24$ and rising emergency admission risk among older age groups. ${ }^{25}$ Ethnicity codes across the three sites were recoded into six categories (Asian or Asian British, black or black British, mixed background, white, unknown and other). Deprivation scores were derived for each individual based on postcode data and use of the Index of Multiple Deprivation 2010 and then 


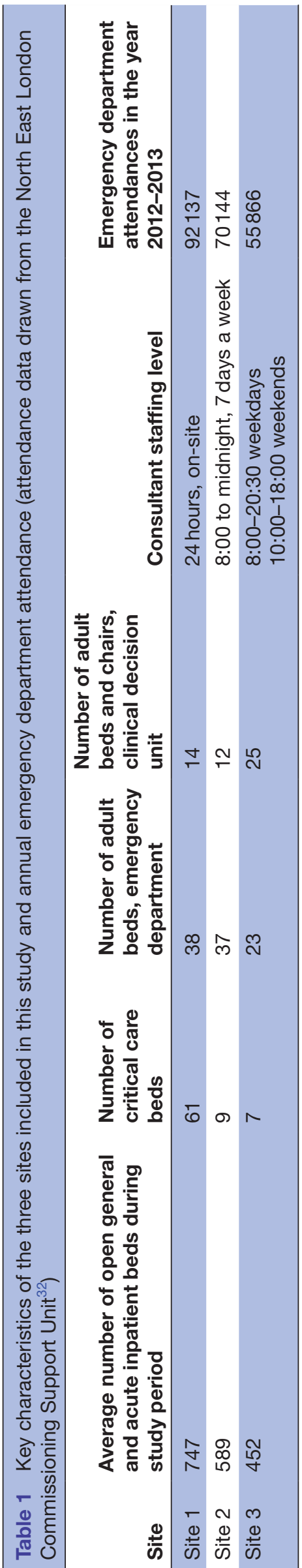

assigned a quintile score based on rankings across the three sites (table 2) ${ }^{26}$ Outcome data relating to admission to the observational unit at site 3 were adjusted by recoding those patients identified as 'admitted as inpatient' (admission outcome) and 'A\&E' (admitting team) or 'Obs Unit' (admission location) and relabelling them as CDU admissions, to bring them into line with the other two sites.

\section{Generation of proxy variables for ED workload, hospital workload and staffing levels}

Various proxy measures of for ED workload have been developed and some validated, but consensus on the most robust measures of crowding does not yet exist. ${ }^{27-29}$ Thus, a range of derived measures were included to test the strength of association with admission or discharge, using arrival time data to derive measures at each hour during the day throughout the month, as outlined in table 2.

For each patient, the value for each of these variables corresponding to the patient arrival time was selected as the proxy for ED workload during their time in the department. Inpatient bed occupancy rate by day of arrival at each site was also incorporated (hourly data were not available). Finally, staffing information for each site (table 1) was used to derive a variable for the presence or absence of a consultant on duty (consultant present or absence). Additional workforce variables capturing, for instance, junior doctor and nurse staffing rates, were not included because the complexity of rotas could not readily be codified in variable form for a cross-sectional analysis.

\section{Outcomes}

The single outcome of interest in this analysis was emergency admission (both inpatient and CDU), which was coded as a binary variable.

\section{Analysis}

Data were summarised in IBM SPSS Statistics V.22.0 using simple cross-tabulations and ORs calculated from these tables including adjustment for confounders to identify potential associations of interest. In order to exclude the possibility of significant multicollinearity between workload variables given the method by which these were derived, diagnostic tests were performed in SPSS; no significant collinearity was demonstrated between them. Data were then analysed with binary logistic regression used to estimate adjusted ORs (AORs) for the single outcome variable identified above, in two models as follows:

- Model 1: risk of admission adjusted for potential patient demographic and arrival mode confounders (gender, age, ethnicity, deprivation quintile, arrival by ambulance or otherwise, site and shift during which the patient arrived). We used white British as the reference ethnic group for regression analyses.

- Model 2: risk of admission adjusting for the staffing and workload measures outlined above (with, 
Table 2 Definitions for derived variables for ED and hospital workload and staffing factors used in this analysis

\begin{tabular}{|c|c|c|}
\hline Variable & Variable type & Definition \\
\hline IMD score & Categorical & $\begin{array}{l}\text { Quintile } 1 \text { (least deprived)-IMD score }<24.94 \\
\text { Quintile 2-IMD score } 24.94-34.75 \\
\text { Quintile 3-IMD score 34.76-41.05 } \\
\text { Quintile 4-IMD score 41.06-48.33 } \\
\text { Quintile 5 (most deprived) - IMD score }>48.33\end{array}$ \\
\hline ED bed occupancy rate & Continuous & $\begin{array}{l}\text { Ratio of patients in the department in any given hour during the day, to the } \\
\text { number of adults beds in the ED (see table 1) }\end{array}$ \\
\hline Arrival intensity & Continuous & $\begin{array}{l}\text { Raw number of patients arriving in the department during each hour of the } \\
\text { day }\end{array}$ \\
\hline Ambulance arrival intensity & Continuous & $\begin{array}{l}\text { Ratio of patients arriving in the department by ambulance in any given hour, } \\
\text { to the total number of patients arriving in that hour }\end{array}$ \\
\hline 'Left without being treated' & Continuous & $\begin{array}{l}\text { Number of patients who left without treatment in any given hour as a } \\
\text { proportion of all those leaving within the same hour }\end{array}$ \\
\hline Late discharge & Binary & $\begin{array}{l}\text { Positive score (1) applied to each patient who left the department between } \\
230 \text { and } 240 \text { min of initial attendance time. This measure was derived to } \\
\text { investigate the impact of the } 4 \text {-hour quality indicator on admission }\end{array}$ \\
\hline Inpatient bed occupancy rate & Continuous & $\begin{array}{l}\text { Proportion of general and acute medical beds occupied within each hospital, } \\
\text { each day of the month. Figures are reported at 9:00 every day }\end{array}$ \\
\hline Consultant on duty & Binary & $\begin{array}{l}\text { Positive score (1) applied to each record for which a consultant was on duty } \\
\text { at the time of arrival in the ED }\end{array}$ \\
\hline
\end{tabular}

ED, emergency department; IMD, Index of Multiple Deprivation.

again, white British used as the reference group for the ethnicity categorical variable), in addition to the patient variables listed in model 1 . In view of uncertainty over the value of including different workload variables, a stepwise approach was taken to inclusion or exclusion of workload variables from the model, using a backward elimination approach in which only those variables with a $p$ value less than 0.05 were retained.

\section{RESULTS}

\section{Descriptive statistics}

The dataset comprised 19734 unique patient attendances, for which some basic descriptive statistics are summarised in tables 3 and 4 below. Of these unique attendances, $844(4 \%)$ were coded as either 'unplanned' or 'planned' follow-up attendances, and on average, $8 \%$ of patients at each site attended on more than one occasion in a calendar month.
Most of these presentations (66\%) occurred during day shifts, defined as covering a time of arrival between 8:00 and 20:00. There was some variation in attendance rates across the week with higher attendance on Monday, Tuesday and Sunday at all three sites. A greater proportion (44\%) of patients arrived at site 2 by ambulance, compared with sites 1 and 2 (30\% and 36\%, respectively). Age bands for the patients presenting showed a skew toward younger age groups compared with national data, which is consistent with the urban and mobile populations of the areas served by the three sites, although the age profile at site 2 is notably older at site 2 , with $9 \%$ in the 'oldest old' age group compared with $2 \%$ and $3 \%$ at sites 1 and 3, respectively. This observation may partially account for a higher proportion of arrivals by ambulance at site 2 when compared with the other sites.

Ethnicity data were available for 19721 (over 99\%) of the attendances and demonstrated predominantly white or white British populations (46\% of all attendances)

Table 3 Descriptive statistics for ED workload factors, by site

\begin{tabular}{lllllllll}
\hline & Site 1 & & Site 2 & & Site 3 & & ALL & \\
\hline & Median & IQR & Median & IQR & Median & IQR & Median & IQR \\
\hline ED bed occupancy rate & $134 \%$ & $63 \%$ & $97 \%$ & $41 \%$ & $143 \%$ & $74 \%$ & $124 \%$ & $68 \%$ \\
Arrival intensity & 16 & 10 & 9 & 5 & 9 & 6 & 11 & 8 \\
Ambulance arrival intensity & $27 \%$ & $19 \%$ & $43 \%$ & $26 \%$ & $33 \%$ & $28 \%$ & $33 \%$ & $24 \%$ \\
'Left without being treated' intensity & $0 \%$ & $0 \%$ & $0 \%$ & $0 \%$ & $0 \%$ & $8 \%$ & $0 \%$ & $0 \%$ \\
Inpatient bed occupancy rate & $95 \%$ & $2 \%$ & $92 \%$ & $5 \%$ & $96 \%$ & $4 \%$ & $95 \%$ & $5 \%$ \\
\hline
\end{tabular}

ED, emergency department. 


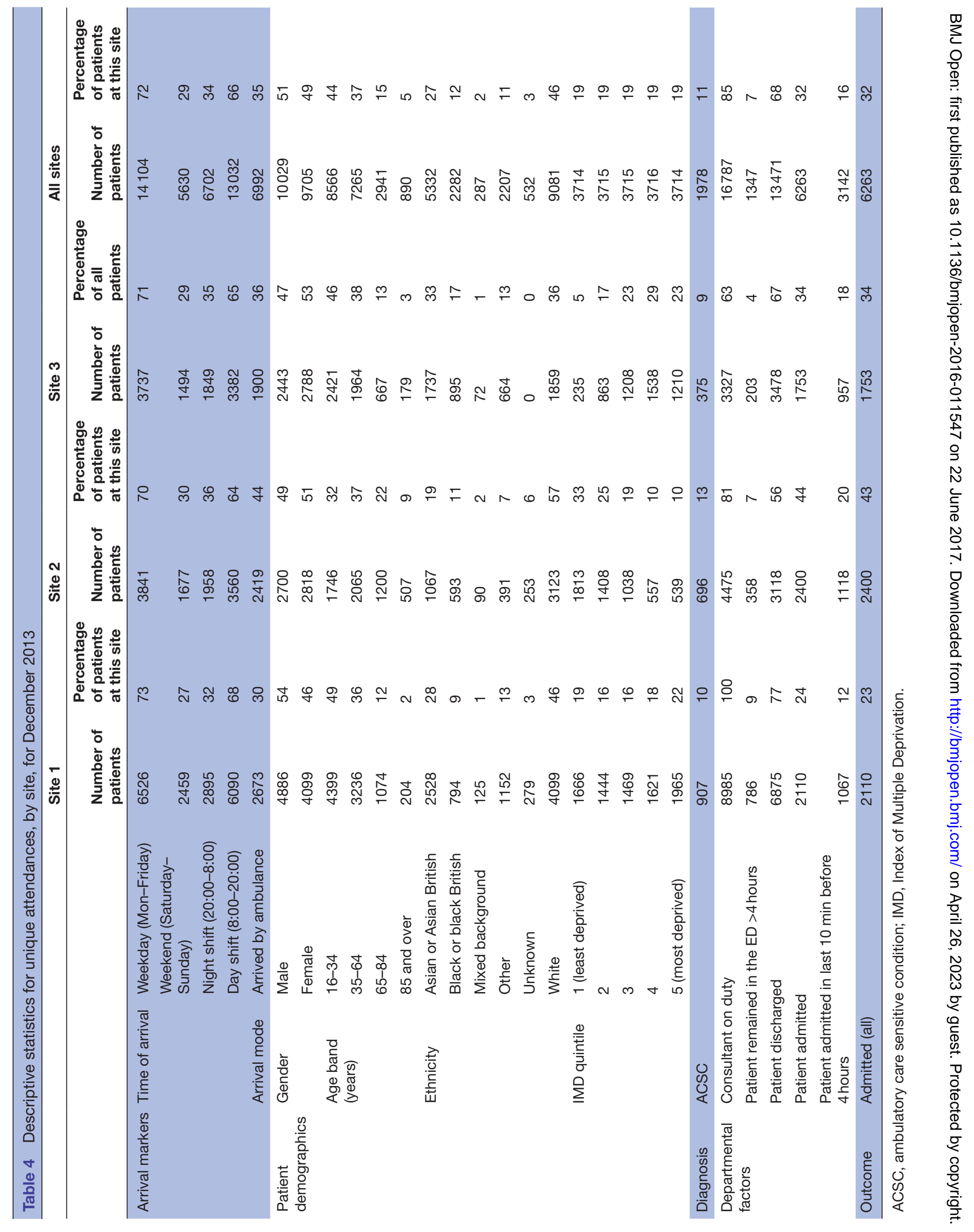


but with significant Asian or Asian British populations across all three sites (27\% of all attendances). One (site 3) showed black or black British patients forming a much larger proportion $(17 \%)$ compared with the other two (9\% and $11 \%$, respectively, for sites 1 and 2).

Diagnoses were available for all unique attendances, but of these, a substantial proportion (over 20\%) described either patient disposition (eg, 'admission to inpatient care', 'venous thromboembolism risk assessment') or were not diagnoses but rather body sites or symptoms (eg, 'abdomen', 'knee' or 'chest pain'). This varied considerably between sites. For example, the code 'admission to inpatient care' accounted for $32 \%$ of final ED diagnoses in site 3, compared with $0.02 \%$ at site 2 . For this reason, ED diagnosis was not included in the regression analyses.

Descriptive statistics for the ED workload measures (continuous variables) generated are given in table 4 .

Outcome data were available for every recorded attendance in the study period. Of the 19734 unique attendances, 6263 (around 32\%) resulted in admission, but with large differences in outcome across the three sites, with around $43 \%$ of all presentations resulting in inpatient admission at site 2, as opposed to $23 \%$ at site $1 \%$ and $33 \%$ at site 3 .

Binary logistic regression results are presented in table 5. Analysis of patient factors revealed that those of black or black British ethnicity were significantly more likely to be admitted as inpatients when adjusting for all other factors (including hospital site); black or black British patients had an AOR for admission of 1.29 (95\% CI 1.16 to $1.44, \mathrm{p}<0.001$ ) in model 1 . Odds of admission for other ethnic groups were not found to be significantly greater than the baseline group (white) in this analysis. Age was strongly associated with admission outcome, with rising AORs for admission with increasing age, especially among the 'oldest old'. Female patients were marginally more likely to be admitted as inpatients in both models (AOR $1.16,95 \%$ CI 1.08 to $1.24, \mathrm{p}<0.001$ in model 1 ). Increasing deprivation was strongly associated with higher risk of admission in this analysis. Analysis of patient presentation factors demonstrated greatly increased odds of admission if a patient arrived by ambulance (AOR 2.89, 95\% CI 2.69 to $3.10, \mathrm{p}<0.001$ in model 1 ). Neither arrival day (weekday vs weekend) nor shift exerted a significant effect in model 1 or 2. Patients presenting with an ambulatory care sensitive condition (ACSC) were at greater risk for inpatient admission when compared with all other presentations and adjusting for other factors (AOR 1.27, 1.14 to $1.41, \mathrm{p}<0.001$, in model 1 ).

Results relating to organisational factors in model two demonstrated statistically significant differences in AORs for admission by site, with odds of admission being greater at sites 2 and 3 than site 1 (and particularly so for site 2, AOR $1.89,95 \%$ CI 1.74 to $2.05, \mathrm{p}<0.001$, in model 1). This observation held even when controlling for departmental load factors in model 2 (AOR for site 2 was greatest in both models: AOR 1.75 in model 2, 95\% CI 1.60 to $1.92, \mathrm{p}<0.001)$. However, analysis of various workload-related factors gave conflicting results with respect to admission risk. In this analysis, both left without being treated (LWBT) intensity (AOR 1.83, 95\% CI 1.10 to $3.04, \mathrm{p}<0.05)$ and particularly disposition decision in the $10 \mathrm{~min}$ leading up to the 4 -hour target $(3.61,3.30$ to 3.95 , $\mathrm{p}<0.001)$ were markers of risk of emergency admission. By contrast, high ED bed occupancy rate marginally reduced the risk of admission (AOR 0.80, 95\% CI 0.74 to $0.87, \mathrm{p}=0.001$ ). Arrival intensity (both in total and by ambulance alone) and inpatient bed occupancy rate had no discernible effect on admission risk and were removed from model 2 to improve fit. In this analysis, presence of a consultant conferred an increase in risk of admission when controlling for other factors (AOR 1.24, 1.08 to $1.41, \mathrm{p}<0.05)$.

\section{DISCUSSION}

This analysis found statistically significant differences in odds of admission between sites which could not be explained by a range of patient demographic, patient presentation and workload-related factors. Explanations for the magnitude of the difference in admission risk between sites are not immediately apparent. Although a greater proportion of patients attending at site 2 arrived by ambulance and were in the oldest age group (65 and older), odds of admission remain significantly different between sites even when controlling for these variables. However, our accompanying qualitative analysis of organisational factors suggests that cultural factors may be important; respondents identified additional management pressures at site 2 and a less supportive environment for junior staff as important factors in explaining admission risk ${ }^{22}$. Deconstructing the 'cultural' factors that may contribute to admission risk is an important area for future research. Analysis of demographic factors in this study corroborates results from analyses elsewhere, notably the clear relationship between rising deprivation level and admission risk fits with findings from a range of other studies ${ }^{45-9}$, and the increased risk of admission observed for patients of black or black British ethnicity, a strong association possibly reflecting the particular burden of chronic disease morbidity in these patients.

These findings suggest that other ED-related and clinician level behaviours may play an important role in admission rates. In particular, the strength of the observed relationship between late discharge (ie, patients who leave the ED in the $10 \mathrm{~min}$ preceding the 4-hour target) and risk of admission suggests that the 4-hour waiting time target for EDs in England influences decisions to admit. Clinicians may be admitting patients they had expected to discharge, as they were unable to complete their diagnostic and/or therapeutic workup in the 4-hour time frame. Conflicting findings from analysis using a variety of ED workload measures, some of which (eg, LWBT intensity and ED bed occupancy rate) are regarded as well-validated measures, suggest that caution should be exercised in using quantitative proxies for 


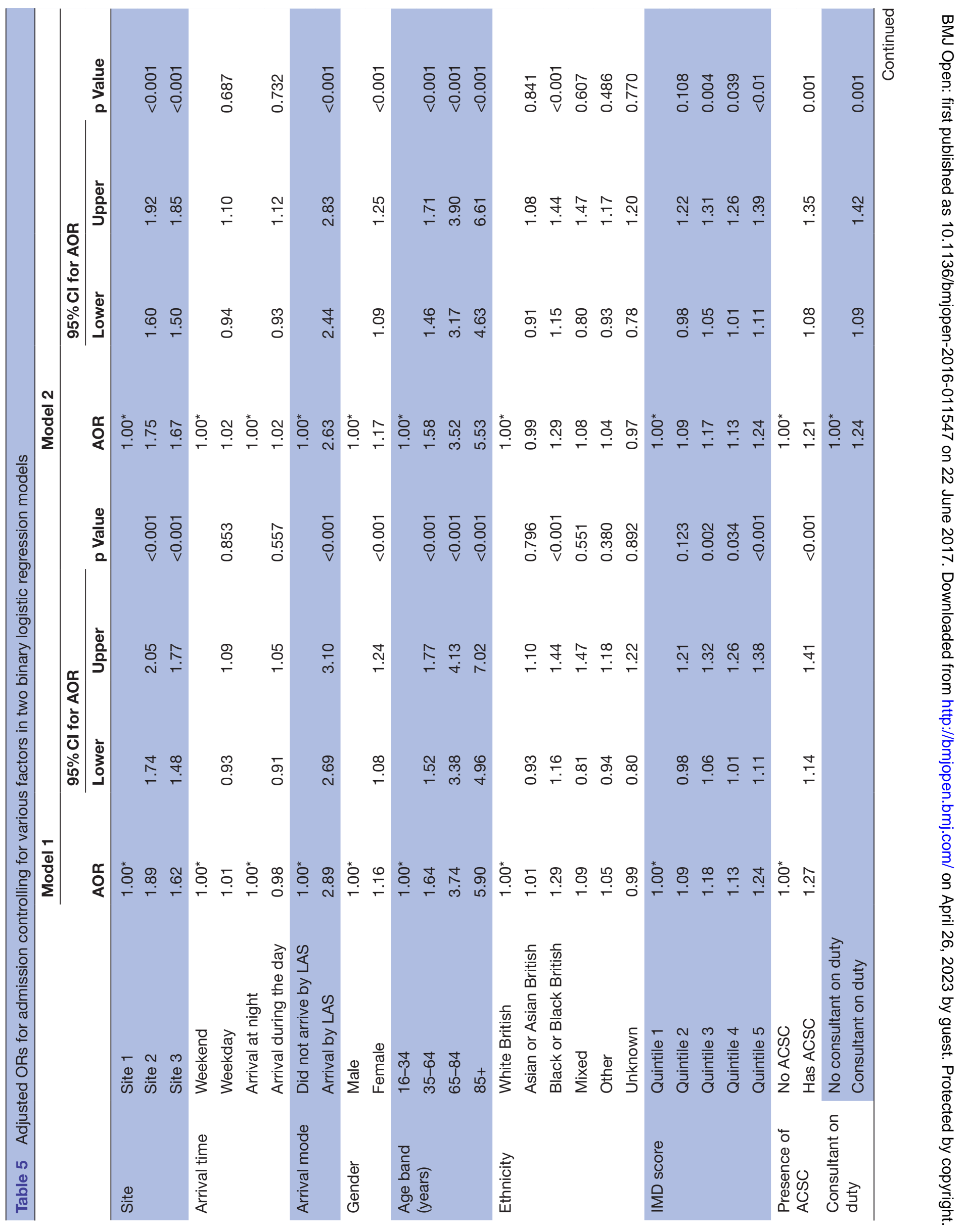




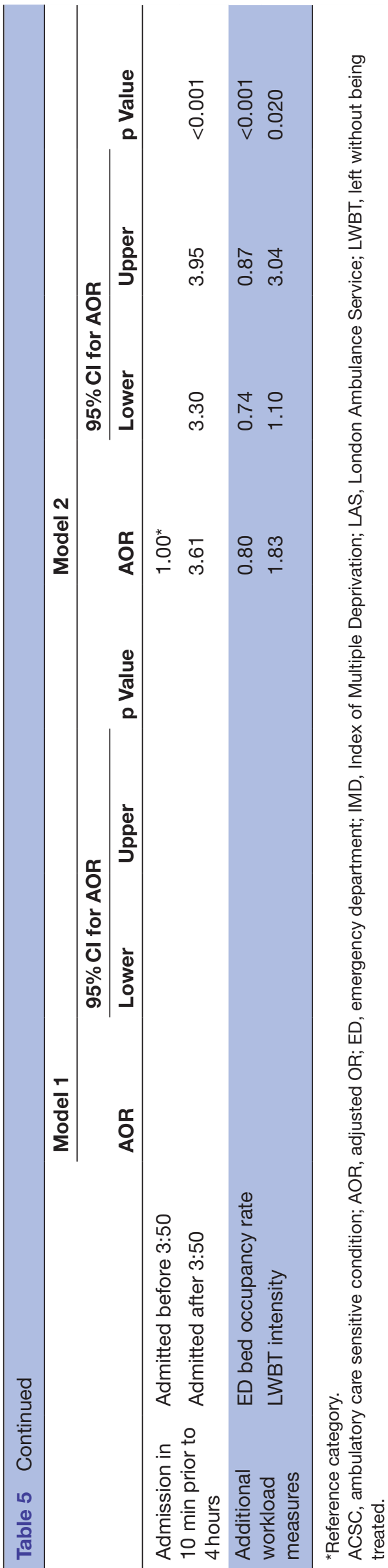

workload. Nevertheless, results suggest that knowledge of high bed occupancy in the ED may dissuade clinical teams from admitting patients, although no relationship with inpatient bed occupancy was demonstrated.

\section{Strengths and limitations of the analysis}

This cross-sectional analysis of attendance data from three EDs in England is among the first to use routine ED data to develop a multidimensional view of patient-related, presentational and department workload factors that may influence admission decision making. However, the use of routine ED data exposed significant problems with coding and definitions that have been discussed elsewhere, ${ }^{30}$ and the absence of patient diagnosis and comorbidity data is a major limitation to this analysis. Both factors may have an important bearing on admission risk. However, the selection of three hospital sites serving similar parts of London where we would not expect to see systematic differences in the quality of primary care, and analysis of data on a large number of attendances (approaching 20000) of varying acuities suggests that patient case-mix is unlikely to fully account for the significant variation in admission risk observed between sites. On the other hand, this may limit the generalisability of findings, since the selected sites are within relatively close geographical proximity to one another. Second, the use of presentation data covering a single winter month in which there is often significant volatility in emergency attendances is a limitation which might be addressed through inclusion of data covering longer time periods in future studies. ${ }^{31}$ Third, a subset of patients were identified as having presented on multiple occasions across the single month of this study. For the purposes of this analysis, all attendances were treated as unique events, and no supplementary analysis of repeat attenders with (potentially) linked attendance patterns was attempted. Finally, ED workload variables were generated for each patient at a single, fixed time-point and are therefore an approximation. This was particularly the case for inpatient bed occupancy rates, for which only daily bed occupancy rates for each site could be obtained. However, it also applies to measures such as consultant staffing, for which single estimates were generated based on the patient's time of arrival. This may have led to the analysis of some attendances as 'consultant staffed', when in fact a consultant was not on duty when the decision to admit or discharge was made. The cross-sectional design of the study meant that it was not possible in this analysis to model ED workload factors as dynamic variables. Building a more complete picture of variations in risk over time is an important area for further research.

\section{CONCLUSIONS}

In this analysis, risk of inpatient admission was found to be significantly higher at two of the sites when compared with the first, adjusting for a variety of demographic, patient presentation and departmental factors. Risk of admission was also greater for those of black or black 
British ethnicity. Evidence on the role of ED workload factors was conflicting, but the 4-hour target emerges as a strong driver for admission behaviour.

Correction notice This paper has been amended since it was published Online First. Owing to a scripting error, some of the publisher names in the references were replaced with 'BMJ Publishing Group'. This only affected the full text version, not the PDF. We have since corrected these errors and the correct publishers have been inserted into the references.

Contributors IP, DM and TH initiated the project, designed the study and specified the data collection protocol. IP, RC, EG, REL and GJ collected the data. SAl cleaned and transformed the data, incorporated new variables and performed the statistical analysis. SAI and IP drafted and revised the manuscript. DM, BB and TH commented on and revised the manuscript. TH is the guarantor of this study.

Funding None.

Competing interests None declared.

Ethics approval This study was reviewed by the host Trust Research and Development Board. As there were no deviations from usual care, no interventions, no medications and data were both retrospective and were anonymised,no formal IRAS application was required. The study was registered in accordance with Trust guidelines and governance procedures

Provenance and peer review Not commissioned; externally peer reviewed.

Data sharing statement Extra data can be accessed via the Dryad data repository at http://datadryad.org/ with the doi:10.5061/dryad.b1rr1

Open Access This is an Open Access article distributed in accordance with the Creative Commons Attribution Non Commercial (CC BY-NC 4.0) license, which permits others to distribute, remix, adapt, build upon this work non-commercially, and license their derivative works on different terms, provided the original work is properly cited and the use is non-commercial. See: http://creativecommons.org/ licenses/by-nc/4.0/

(c) Article author(s) (or their employer(s) unless otherwise stated in the text of the article) 2017. All rights reserved. No commercial use is permitted unless otherwise expressly granted.

\section{REFERENCES}

1. Purdy S. Avoiding hospital admissions: what does the research evidence say? London, King's Fund. 2010.

2. Blunt I, Bardsley M, Dixon J. Trends in emergency admissions in England 2004-2009: is greater efficiency breeding inefficiency? London: Nuffield Trust. 2010 Online at http://www.nuffieldtrust.org. uk/publications/trends-emergency-admissions-england-2004-2009 (accessed 2/7/15)

3. Bardsley M, Blunt I, Davies S, et al. Is secondary preventive care improving? Observational study of 10-year trends in emergency admissions for conditions amenable to ambulatory care. BMJ Open 2013;3:e002007.

4. House of Commons Library. Accident and Emergency Statistics. London: House of Commons Library, 2015. Briefing Paper No. 6964.

5. Bottle A, Aylin P, Majeed A. Identifying patients at high risk of emergency hospital admissions: a logistic regression analysis. J $R$ Soc Med 2006;99:406-14.

6. Reid FD, Cook DG, Majeed A. Explaining variation in hospital admission rates between general practices: cross sectional study. BMJ 1999;319:98-103.

7. Gilthorpe MS, Lay-Yee R, Wilson RC, et al. Variations in hospitalization rates for asthma among black and minority ethnic communities. Respir Med 1998;92:642-8.

8. Hippisley-Cox J, Coupland C. Predicting risk of emergency admission to hospital using primary care data: derivation and validation of QAdmissions score. BMJ Open 2013;3:e003482.

9. Billings J, Blunt I, Steventon A, et al. Development of a predictive model to identify inpatients at risk of re-admission within 30 days of discharge (PARR-30). BMJ Open 2012;2:e001667.
10. Howell S, Coory M, Martin J, et al. Using routine inpatient data to identify patients at risk of hospital readmission. BMC Health Serv Res 2009;9:96.

11. Roland M, Abel G. Reducing emergency admissions: are we on the right track? BMJ 2012;345:e6017.

12. Cecil E, Bottle A, Sharland M, et al. Impact of UK primary care policy reforms on short-stay unplanned hospital admissions for children with primary care-sensitive conditions. Ann Fam Med 2015;13:214-20.

13. Ismail SA, Gibbons DC, Gnani S. Reducing inappropriate accident and emergency department attendances: a systematic review of primary care service interventions. Br J Gen Pract 2013;63:e813-20.

14. Purdey S, Huntley A. Predicting and preventing avoidable hospital admissions: a review. J R Coll Physicians Edinb 2013;43:340-4.

15. Huntley $A$, Lasserson $D$, Wye $L$, et al. Which features of primary care affect unscheduled secondary care use? A systematic review. BMJ Open 2014;4:e004746.

16. Rossdale M, Kemple T, Payne S, et al. An observational study of variation in GPs' out-of-hours emergency referrals. Br J Gen Pract 2007;57:152-4.

17. Calder LA, Forster AJ, Stiell IG, et al. Mapping out the emergency department disposition decision for high-acuity patients. Ann Emerg Med 2012;60:567-76.

18. Lewis Hunter AE, Spatz ES, Bernstein SL, et al. Factors influencing hospital admission of non-critically ill patients presenting to the emergency department: a cross-sectional study. J Gen Intern Med 2016;31:37-44

19. National Audit Office. Emergency admissions to hospital: managing the demand (London: nao). 2013.

20. Graham J, Aitken ME, Shirm S. Correlation of measures of patient acuity with measures of crowding in a pediatric emergency department. Pediatr Emerg Care 2011;27:706-9.

21. Blom MC, Jonsson F, Landin-Olsson M, et al. The probability of patients being admitted from the emergency department is negatively correlated to in-hospital bed occupancy-a registry study. Int J Emerg Med 2014;7:8.

22. Pope I, Burn $\mathrm{H}$, Ismail $\mathrm{S}$, et al. A qualitative study exploring the factors influencing admission to hospital from the emergency department. BMJ Open

23. Melzer D, Tavakoly B, Winder RE, et al. Much more medicine for the oldest old: trends in UK electronic clinical records. Age Ageing 2015;44:46-53.

24. Gale CR, Cooper C, Sayer AA. Prevalence of frailty and disability: findings from the English Longitudinal Study of Ageing. Age Ageing 2015;44:162-5.

25. Wittenberg R, Sharpin L, McCormick B, et al. Understanding emergency hospital admission of older people. Oxford: Centre for Health Service Economics and Organisation,. 2014 www.chseo. org.uk/downloads/report6-emergencyadmissions.pdf (accessed 13/5/16).

26. Department for Communities and Local Government. English indices of deprivationOnline at. 2010 https://www.gov.uk/government/ statistics/english-indices-of-deprivation-2010 (accessed 2/7/15).

27. Hoot NR, Aronsky D. Systematic review of emergency department crowding: causes, effects, and solutions. Ann Emerg Med 2008:52:126-36.

28. Hwang U, McCarthy ML, Aronsky D, et al. Measures of crowding in the emergency department: a systematic review. Acad Emerg Med 2011;18:527-38.

29. Bernstein SL, Aronsky D, Duseja R, et al. Society for Academic Emergency Medicine, Emergency Department Crowding Task Force. The effect of emergency department crowding on clinically oriented outcomes. Acad Emerg Med 2009;16:1-10.

30. Hughes G. A\&E quality indicators. Emerg Med J 2012;29:90.

31. Fisher $E$, Dorning $H$. Winter pressures: what's going on behind the scenes? London: Nuffield Trust/Health Foundation. 2016. [accessed 4/5/16] http://www.qualitywatch.org.uk/sites/files/qualitywatch/field/ field_document/20151218_QualityWatch_winter_pressures_final_for_ WEB 0.pdf.

32. North East London commissioning support unit.. Transforming Services, Changing Lives: Clinical Working Group Data Pack Unplanned Care. London: North East London Commissioning Support Unit [online at. http://www.transformingservices.org.uk/ downloads/appendices/up/UP\%20Technical\%20data\%20pack.pdf (accessed 13/5/16). 